J. Clin. Chem. Clin. Biochem.

Vol. 25, 1987, pp. 487-492

(C) 1987 Walter de Gruyter \& Co. Berlin · New York

\title{
Non-Separation Radioassay for Cortisol Binding Capacity in Human Serum
}

\author{
By R.S. Salem
}

Endocrinology Unit, Sabah Hospital, Ministry of Public Health, Kuwait

Mithal Hassan

Department of Nuclear Medicine, Faculty of Medicine, Kuwait University

M. A. Al-Awqati, M. Abu-Omeir

Endocrinology Unit, Sabah Hospital, Ministry of Public Health, Kuwait

Daisy Issac and H. M. Abdul-Dayem

Department of Nuclear Medicine, Faculty of Medicine, Kuwait University

(Received July 28, 1986/February 10, 1987)

Summary: A radioassay for the measurement of cortisol binding capacity in human serum was developed and the results validated by radioimmunoassay of serum corticosteroid binding globulin. The mini-scale method is simple, reliable and rapid, and avoids separation of partitioned phases. The linear correlation between the free cortisol index and free cortisol concentration as calculated by the two methods utilizing serum samples with normal and abnormal protein concentrations was $r=0.962(n=114, p<0.001)$ and the regression equation was $y=3.516 x-2.632$. The technique requires no preparation of reagents, and the assay can be performed in 45 minutes using $0.05 \mathrm{ml}$ of serum or plasma.

\section{Introduction}

Corticosteroid binding globulin (CBG; synonym transcortin) binds cortisol, ảnd to a lesser extent some other steroids, with relatively high affinity and low capacity. The physicochemical characteristics and clinical relevence of this protein have been comprehensively reviewed elsewhere $(1,2)$. Cortisol circulates in the human blood stream in bound (about $75 \%$ of total cortisol tightly to corticosteroid binding globulin and $10 \%$ loosely to albumin) and unbound fractions. Measurement of the latter in plasma is considered to be clinically more appropriate, since it reflects the physiologically active form of the circulating cortisol, and provides reliable information, especially in cases of altered corticosteroid binding globulin levels. Measurement of the unbound fraction is therefore expected to become a frequently ordered test.
In recent years, assays of salivary cortisol have been advocated as a reliable alternative test for assessing adrenal status, since direct techniques for the measurement of unbound "free" cortisol in plasma are not available (3). For serum samples, the most common methods so far described involve the combined estimation of total plasma cortisol and its free fraction estimated by one of the following techniques: binding capacity by equilibrium dialysis (4), ultrafiltration (5), steady state gel filtration (6) or dextran coated charcoal (7); other methods rely on the measurement of total cortisol and direct estimation of corticosteroid binding globulin by immunochemical or radioimmunoassay (RIA) techniques $(8,9)$. The major disadvantages of these methods include cumbersome procedures, preparation of special reagents, unsuitability for automation, relatively large sample volumes or high cost. 
We describe the development of a reliable, inexpensive and basically versatile technique for the measurement of patient plasma/serum binding capacity for cortisol, which can be used in conjunction with the total cortisol level to estimate the free cortisol.

\section{Subjects, Materials and Equipment}

Subjects

Morning blood samples $(10 \mathrm{ml})$ were obtained during fasting from 13 male and 18 female volunteers (not using oral contraceptives), 22 samples from 11 patients before and 12 hours after a single oral dose $(1.0 \mathrm{mg})$ of dexamethasone (Roussel Lab. Ltd., London, U. K.), 15 samples from 5 patients subjected to a short synacthen test (i. v. injection of $0.25 \mathrm{mg}$ tetracosactide: cortrosyn ${ }^{\circledR}$; Organon, Oss, Holland), 24 morning and evening samples from 12 patients, and 22 samples from pregnant women at various stages of gestation (15-40 weeks). The serum samples were stored at $-20^{\circ} \mathrm{C}$ until assayed.

\section{Materials}

All "Analar" grade chemicals and solvents were obtained from BDH chemical's (Poole, U. K.). $\left[1,2,6,7-{ }^{3} \mathrm{H}\right]$ cortisol, $3145 \mathrm{GBq} /$ mmol in $(9: 1)$ toluene: ethanol (cat. no. 407) was obtained from Amersham International (Bucks, U.K.), and unlabelled cortisol was from Steraloids Ltd. (Croyden, U.K.). Total cortisol RIA kits were obtained from Corning Medical and Scientific (Medfield, Massachusettes 02052, USA) and CBG RIA kits from Institute National Des Radioelements (Fleurus, Belgium).

Phosphate buffer, $0.1 \mathrm{~mol} / 1 \mathrm{pH} 8.0$, was used throughout unless otherwise stated. Toluene containing $4 \mathrm{~g} / 1$ 2,5-diphenyloxazole (PPO) and $0.04 \mathrm{~g} / 1$ 1,4-bis2-(4-methyl-5-phenyloxazole) benzene (DM-POPOP) was used as a scintillant.

\section{Equipment}

Beta counting was performed with an LKB Rack Beta liquid scintillation counter model 1217 (Bromma, Sweden).

Quench was determined by the channels ratio method, using an external set of quenched standards consisting of 7 ampoules containing different quantities of quenching agent (carbon tetrachloride) and identical amounts of radioactivity (cat. no. QCR 50, Amersham International). Using the quench correction, counts were converted to disintegrations per minute.

Assays were carried out in $15 \times 55 \mathrm{~mm}$ disposable plastic scintillation mini vials obtained from Wheaton Scientific, N. J. 08332, USA.

\section{Methods and Results}

Preparation of corticosteroid binding globulin standards

A pool of late pregnancy serum was obtained from women at over 28 weeks of gestation. Six dilutions were prepared in a pool of male serum which had been preheated at $60^{\circ} \mathrm{C}$ for 2 hours. The corticosteroid binding globulin concentrations of these standards were estimated by a modification of the Rosner method (10) where the binding protein is saturated with tritiated cortisol then precipitated with ammonium sulphate, and the mass of bound cortisol is determined from the known specific activity of the added steroid. The standards (with an assigned value of $35,70,150,300,700$, and $1500 \mathrm{nmol} / \mathrm{l}$ ) were aliquoted and stored at $-20^{\circ} \mathrm{C}$ until used.

\section{Principle of the method}

A fixed quantity of buffered ${ }^{3} \mathrm{H}$-labelled cortisol is added to all samples and standards. After equilibrium is attained, a fixed volume of toluene-based scintillation liquid is added, followed by short vortex mixing and the radioactivity estimated in a liquid scintillation counter at $4^{\circ} \mathrm{C}$.

The unbound cortisol immediately becomes partitioned into the organic solvent while protein-bound cortisol remains within the aqueous phase. The aqueous fraction makes no contribution to the photon yield of the scintillation system. Hence; a direct relationship exists between the amount of ${ }^{3} \mathrm{H}$ labelled cortisol bound to plasma proteins (mainly corticosteroid binding globulin) and the decrease of total radioactivity.

This principle is supported by the following facts:

1. The observed quenching process is not associated with a concomitant shift in the ${ }^{3} \mathrm{H}$ energy spectrum (fig. 1); and

2. A linear Scatchard plot is obtained when dialysed serum pools are incubated with varying quantities of ${ }^{3} \mathrm{H}$-labelled cortisol (fig. 2).

\section{Optimization of assay conditions}

\section{Scintillant volume}

Three concentrations of ${ }^{3} \mathrm{H}$-labelled cortisol with various scintillant volumes ranging from 0.5 to $3.5 \mathrm{ml}$ were counted. A plateau was reached at about $2.5 \mathrm{ml}$ of scintillant (fig. 3), indicăting no significant gains in counting efficiency if the volume of the scintillant was further increased. This volume was therefore used in all subsequent studies.

\section{Effect of $p H$ and incubation time}

Using pregnancy or normal serum pools, $0.2 \mathrm{ml}$ of buffered ${ }^{3} \mathrm{H}$-labeled cortisol $(660 \mathrm{~Bq})$ was incubated at $37^{\circ} \mathrm{C}$ with $0.05 \mathrm{ml}$ of serum, followed by addition of $2.5 \mathrm{ml}$ of scintillant in one set, buffers of various $\mathrm{pH}$ ranging from 4 to 10 were used, while in the second set, assay tubes were incubated for various periods of time ranging from 0 to $120 \mathrm{~min}$. A pH of 8.0 and an incubation time of 30 minutes were found to be optimal as shown in figures 4 and 5 respectively.

\section{Dissociation rate of binding protein-corti- sol complex}

Using the optimized conditions described above, a standard curve was constructêd, and serial counting 


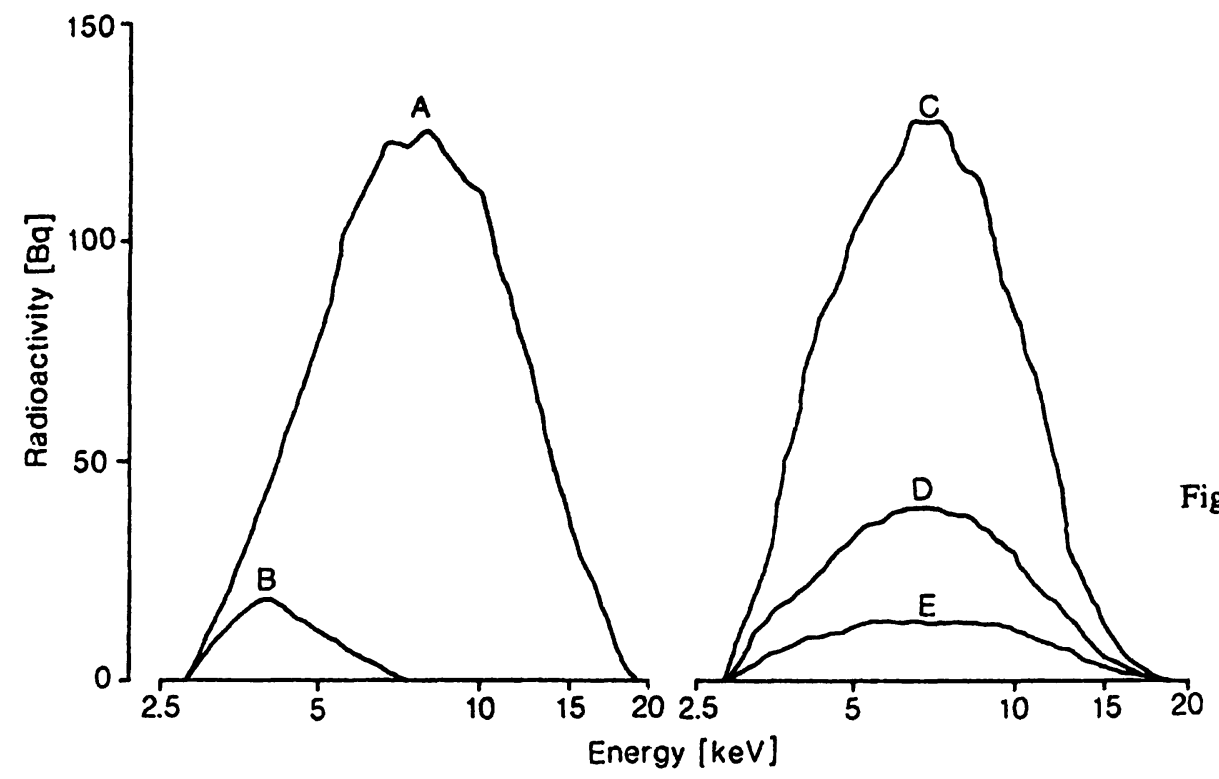

Fig. 1. Energy spectrum of unquenched (A), and heavily quenched (B) tritium standards, and a fixed quantity of $[\mathrm{H} \mathrm{H}]$ cortisol in phosphate buffer (C), in a pool of male serum (D), and in a pool of pregnancy scrum (E).

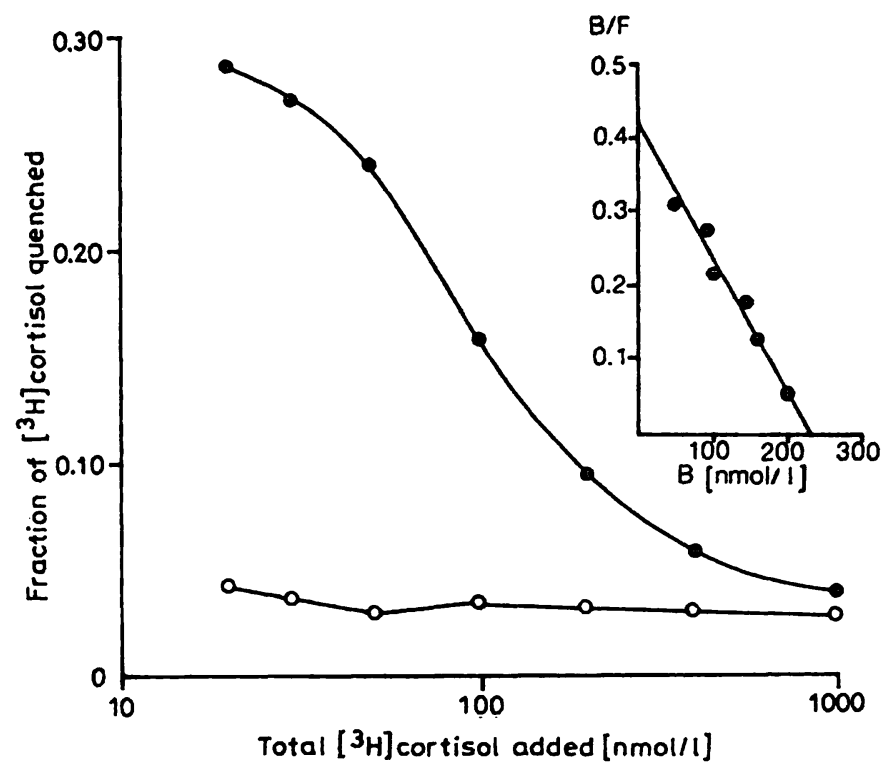

Fig. 2. Binding of $\left[{ }^{3} \mathrm{H}\right]$ cortisol to a pool of normal serum either alone ( 0 ) or in the presence of 100 -fold molar excess of unlabelled cortisol (0). Saturable binding, calculated as the difference between the results in the presence and absence of excess unlabelled cortisol, is represented by the method of Scatchard in the inset. Equilibrium constant $\left(\mathrm{K}^{-1}\right.$ at $\left.37^{\circ} \mathrm{C}\right)=548 \mathrm{nmol} / 1$.

of radioactivity was performed immediately and after 100 minute intervals. The fraction of decrease in quenching was found to be 0.045 per hour at the lowest end and 0.072 per hour at the highest end of the standard curve. However, these rates were gradually reduced to less than 0.01 per hour after the first five hours. Thus, the effect of such dissociation was deemed relèvant only for largè routine assays, where under these circumstances either the standard curve is counted repeatedly after every 30 samples or

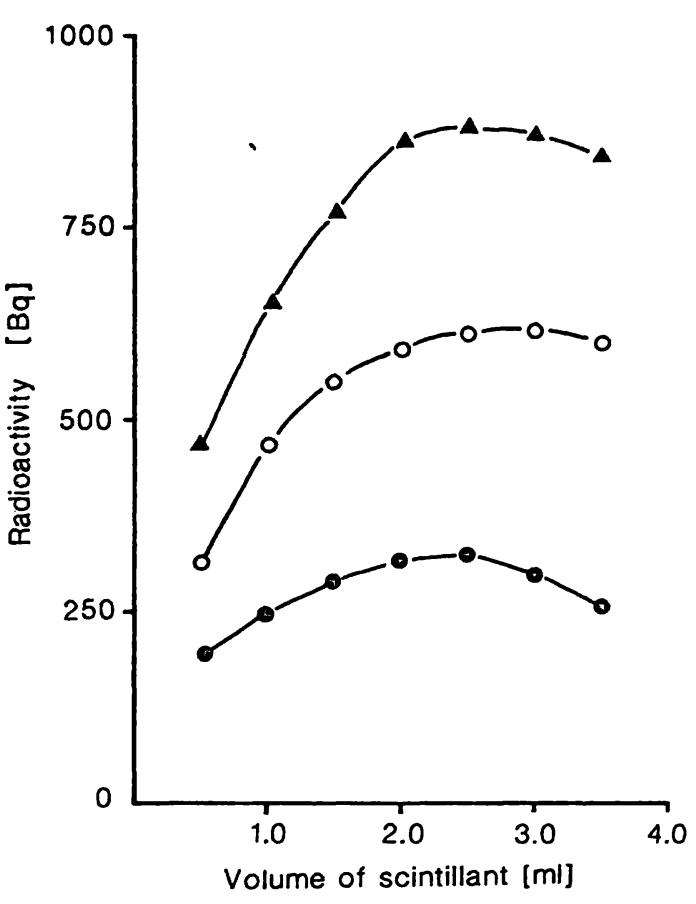

Fig. 3. The effect of increasing scintillant volume on the total counts of a fixed quantity of [ $\left.{ }^{3} \mathrm{H}\right]$ cortisol containing 330 $(\bullet), 660(0)$, and $1320(\Delta) \mathrm{Bq}$.

counting of the whole assay is delayed for 3 hours after toluene addition.

\section{Haemolysis}

Heparinized erythrocytes were washed with saline and subjected to 3 cycles of freezing and thawing. The haemoglobin content of the haemolysate was determined and incremental amounts of it were added 


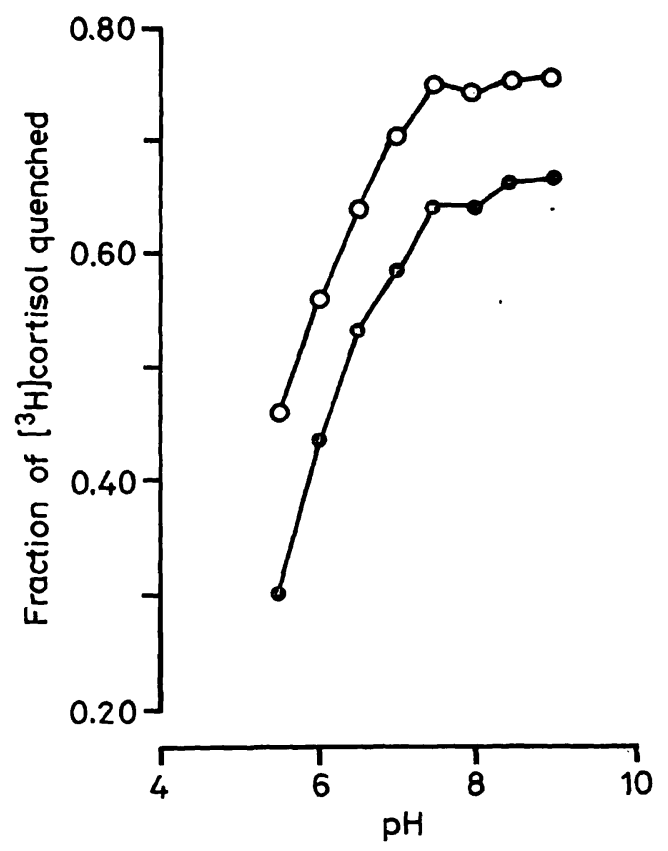

Fig. 4. The effect of $\mathrm{pH}$ on the binding (expressed as fraction of quenching) of $\left[{ }^{3} \mathrm{H}\right]$ cortisol to pools of normal ( $(0)$ and pregnancy $(0)$ sera.

to 3 serum samples which were assayed by the present method. Haemoglobin up to $6.5 \mathrm{~g} / 1$ did not appear to interfere with the assay.

\section{Precision}

The within-batch coefficient of variation, assessed by 10 simultaneous analyses of samples with low, normal and high concentration of corticosteroid binding globulin were $8.9,5.2$, and $6.8 \%$ respectively. The between-batch coefficient of variation, assessed by analysis of a normal sample in 5 consecutive assays, was $8.2 \%$.

\section{Final assay protocol}

The assay is carried out in mini vials. Reagents are added in duplicate as follows:

$0.05 \mathrm{ml}$ of standard or patient serum; $0.2 \mathrm{ml}$ of ${ }^{3} \mathrm{H}-$ labeled cortisol $(660 \mathrm{~Bq})$ in phosphate buffer; incubation at $37^{\circ} \mathrm{C}$ for $30 \mathrm{~min}$; addition of $2.5 \mathrm{ml}$ of scintillation liquid. Radioactivity was measured in a liquid scintillation counter. A typical standard curve is shown in figure 6 .

Calculation of Free Cortisol Index: The following equation was utilized for estimating the Free Cortisol Index:

$\mathrm{FCI}=\frac{\text { Serum Total Cortisol (nmol/l) }}{\text { Serum Binding Capacity for Cortisol (nmol/l) }}$

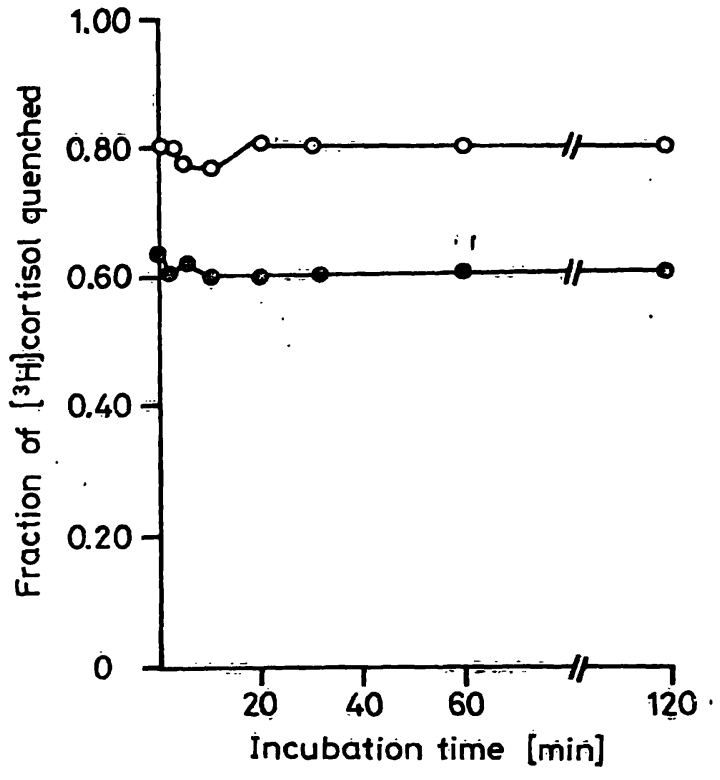

Fig. 5. The effect of increasing incubation time on the binding (expressed as fraction of quenching) of [ $\left.{ }^{3} \mathrm{H}\right]$ cortisol to pools of normal $(0)$ and pregnancy $(0)$ sera.

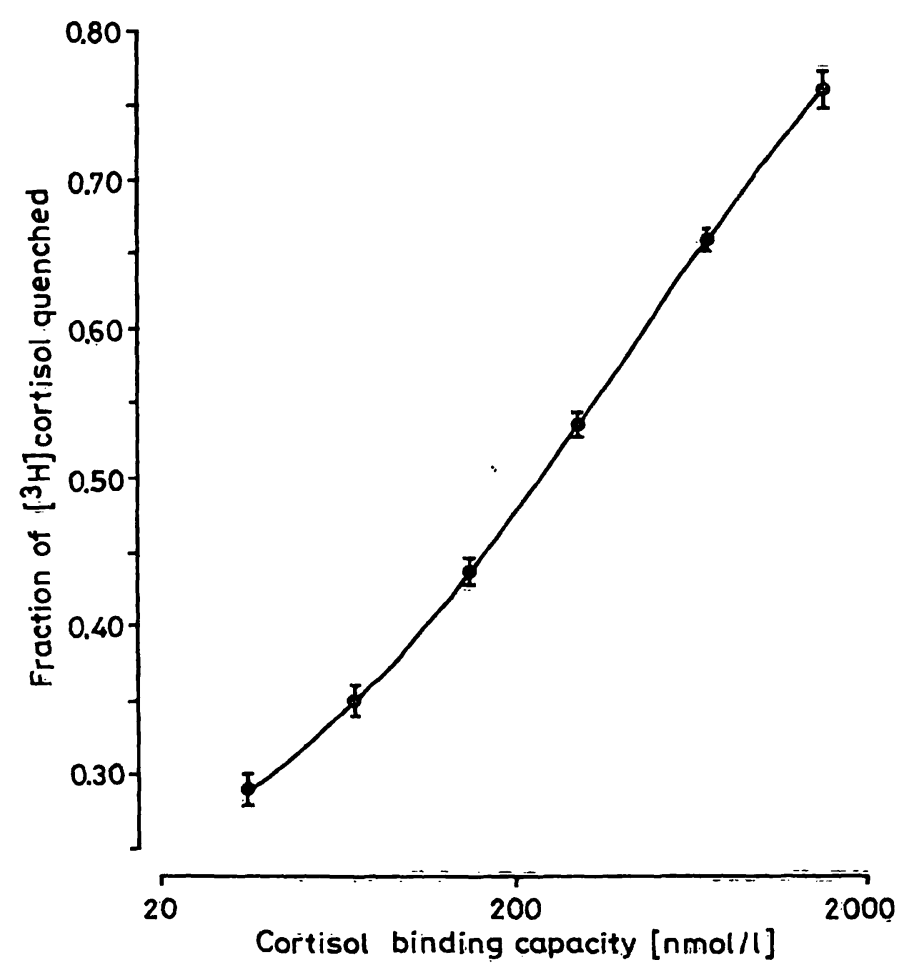

Fig. 6. A typical standard curve for the radioassay of human serum binding capacity for cortisol. Each point represents the mean of triplicate determinations $\pm 1 \mathrm{SD}$.

\section{Corticosteroid binding globulin by radioim- munoassay}

Serum concentrations of corticosteroid binding globulin were measured by a commercial radioimmunoassay kit and the free cortisol concentrations were estimated according to the manufacturer's instruc- 
tions. According to the manufacturer, the validity of such estimations has been proved by comparison with free cortisol levels determined by ultrafiltration $(\mathrm{n}=60, \mathrm{r}=0.9444, \mathrm{y}=0.892 \mathrm{x}+1.38 \mathrm{nmol} / \mathrm{l})$.

\section{Clinical observations in normal and patient samples}

As expected, no statistically significant differences were detected in the values for binding capacity or actual corticosteroid binding globulin levels between apparently normal males and females. Furthermore, pregnancy samples exhibited higher levels for both parameters as shown in table 1.

The serum binding capacity was inversely related to changes in cortisol concentrations, e.g. the decrease of cortisol in the dexamethazone suppression test, the rise during the short synacthen test, and the decline in midnight levels (fig. 7).
The relationship between the estimates of free cortisol concentration (obtained from total cortisol and corticosteroid binding globulin concentration) and free cortisol index (obtained from total cortisol and values of binding capacity), shown in figure 8 , gave a correlation coefficient of $\mathrm{r}=0.962$ and a linear regression equation $\mathrm{y}=3.516 \mathrm{x}-2.632$.

These results indicate that the method we have developed has quite acceptable limits of specificity and sensitivity for clinical application.

\section{Discussion}

It is well established that serum cortisol is in a state of dynamic equilibrium with both corticosteroid binding globulin and albumin, and that these two proteins form quantitatively significant dissociable complexes with some other steroid hormones (e. g., progesterone

Tab. 1. Estimated values (mean \pm 1 SD) for total cortisol, cortisol binding capacity, corticosteroid binding protein by RIA, free cortisol concentration, and free cortisol index in sera of apparently normal males, females and pregnant women.

\begin{tabular}{|c|c|c|c|c|c|c|c|}
\hline & $\begin{array}{l}\text { Normal } \\
\text { males }\end{array}$ & & $\begin{array}{l}\text { Normal } \\
\text { females }\end{array}$ & & $\begin{array}{l}\text { Normal } \\
\text { pregnanc }\end{array}$ & & \\
\hline No. of subjects & 13 & & 18 & & 22 & & \\
\hline Total cortisol [nmol/1] & 396 & \pm 68 & 365 & \pm 120 & 613 & \pm 18 & \\
\hline Cortisol binding capacity & 838 & \pm 169 & 890 & \pm 162 & 1170 & \pm 2 & \\
\hline CBG by RIA [nmol/l] & 1191 & \pm 103 & 1250 & \pm 113 & 1611 & \pm 3 & \\
\hline Free cortisol concentration & $14.6=$ & $\pm \quad 5.6$ & $12.4=$ & $\pm \quad 4.8$ & 18.3 & \pm & 5.0 \\
\hline Free cortisol index & $0.502=$ & 0.193 & $0.427=$ & 0.196 & 0.515 & \pm & 0.200 \\
\hline
\end{tabular}

$\mathrm{CBG}=$ corticosteroid binding globulin

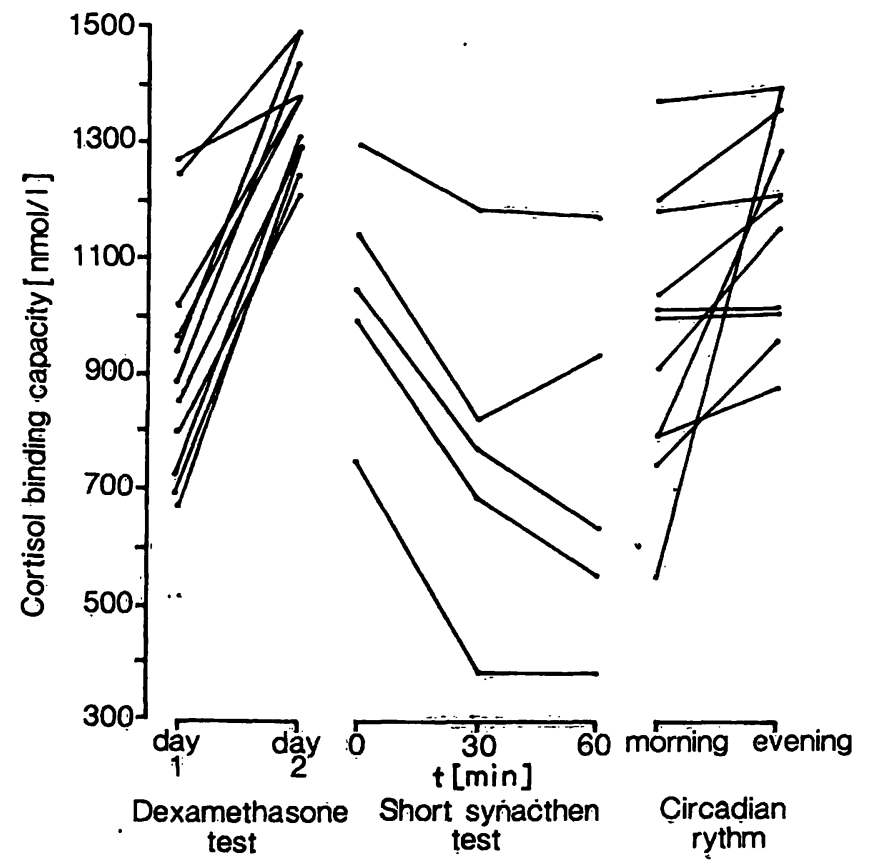

Fig. 7. Comparison of values for cortisol binding capacity in patient's matched samples during the dexamethasone suppression test, the short synacthen test, and circadian rhythm.

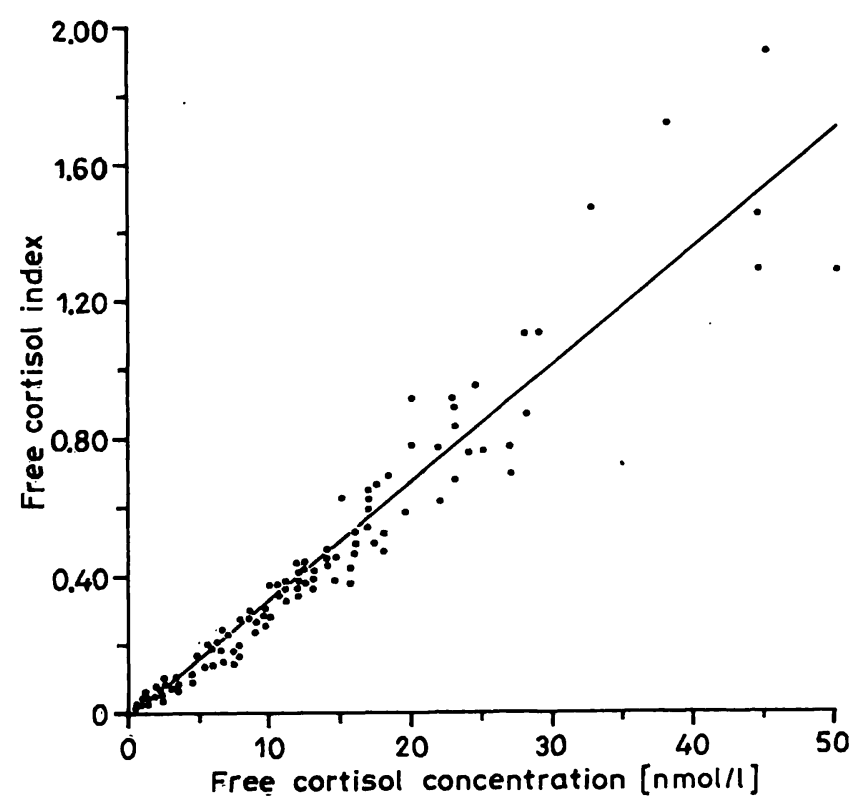

Fig. 8. A scatter plot showing the correlation between the free cortisol concentrations and indices, together with the linear regression. 
(11)). Furthermore, there are many clinical situations (including for example pregnancy, nephrotic syndrome, hepatic diseases $(12,13)$ ) in which, because of altered serum protein binding capacity for cortisol, commonly performed assays of serum total cortisol may provide a poor index of adrenocortico-metabolic status. Direct techniques for the measurement of the biologically active free cortisol are as yet unavailable. An alternative approach to the estimation of this free fraction is based on the law of mass action, and it can be calculated if the concentrations of both serum total cortisol and either corticosteroid binding globulin or measure of the protein binding capacity for cortisol are known.

However, in contradistinction to corticosteroid binding globulin measurement by radioimmunoassay, which admittedly offers better technical levels of sensitivity and specificity, the serum binding capacity technique should provide, on theoretical grounds at least, clinically more relevant estimates of the free cortisol fractions in patient sera, since it takes into account the following:

1. variable serum albumin binding capacity;

2. the presence of other competing biological and/or synthetic steroids;

3. aggregated/non binding molecular forms of corticosteroid binding globulin;

4. immunologically distinct but active genetic variants of corticosteroid binding globulin if present.

Thus, the method we have developed measures serum binding capacity for cortisol, and is based on the principle of competitive binding of tritiated cortisol, under non-saturating conditions, to corticosteroid binding globulin and albumin. It relies on a phase

\section{References}

1. Brien, T. G. (1981) Clin. Endocrinol. 14, 193-212 (Review).

2. Bernutz, C., Hansle, W. O., Horn, K., Pickardt, C. R., Scriba, P. C., Fink, E., Kolb, H. \& Tschesche, H. (1979) Acta Endocrinol. 92, 370-384.

3. Brooks, F. S. \& Brooks, R. V. (1984) Cortisol and cortisone in saliva. In: Immunoassays in saliva (Read, G. F., RiadFahmy, D., Walker, R. F. \& Griffiths, K., eds.) Alpha Omega Publishing Ltd., Cardiff, UK, pp. $322-326$.

4. Baumann, G., Rappaport, G., Lemarchand-Berand, T. \& Felber, J. P. (1975) J. Clin. Endocrinol. Metab. 40, 462469.

5. Jorkunica, I., Sophianopoulos, J. \& Sgoutas, D. (1980) Clin. Chem. 20, 1734-1737.

6. Burke, C. W. (1969) Biochim. Biophys. Acta 170, $403=$ 413.

7. Hammond, G. L. \& Lahteenmaki, P. L. A. (1983) Clin. Chim. Acta 132, 101-110. partition technique to separate bound from free cortisol fractions.

The principal advantages of the present method are: convenience, low cost, long shelf life of reagents, and adequate specificity and accuracy for routine clinical use. The assay requires no conyentional separation step. Automation or predilution of samples are therefore possible, and the assay can be performed in a relatively short time. Furthermore, the total analytical procedure, from mixing the reactants to the actual counting, is performed in one mini vial, with a consequent reduction in cost.

In comparison with other methods, our protocol described here yields values for serum binding capacity for cortisol (230 mmol/l) which are similar to those reported by others (1). In addition, an estimate of the equilibrium constant of cortisol with its binding proteins $(5.48 \mathrm{nmol} / \mathrm{l})$, as obtained by Scatchard analysis of saturation plots, is similar in magnitude to those quoted in the literature $(1,14)$. Furthermore, results of binding capacity obtained by this technique have a highly significant correlation with their corresponding corticosteroid binding globulin estimates by radioimmunoassay.

In conclusion, we have presented a routine laboratory method for measuring serum protein binding for cortisol that can be applied, in conjunction with the concentration of serum total cortisol, to provide valuable information relevant to the diagnosis and/or therapeutic choices in relation to adrenocortical function.

\section{Acknowledgement}

This study was supported by a grant from the Health Research Department, Ministry of Public Health, Kuwait.

8. Hau, J., Westergaard, J. G., Teisner, B., Svendsen, P. \& Grudzinskas, J. G. (1983) Arch. Gynecol. 233, 217-223.

9. Faict, D. \& De Moor, P. (1984) Clin. Chem. 30, 369-372.

10. Rosner, W. (1972) J. Clin. Endocrinol. Metab. 34, 983988.

11. Frey, F. J. \& Frey, B. M. (1984) Am. J. Kidney Dis. 3, $339-348$

12. Talbert, L. M., Pearlman, W. H. \& Potter, H. W. (1977) Am. J. Obstet. Gynecol. 129, $781-786$.

13. Zouaghi, H., Savu, L., Coulon, A. \& Nunez, E. (1984) Clin. Chem. 30, 332-333.

14. Van Baelen, H. \& De Moor, P. (1974) J. Clin. Endocrinol. Metab. 39, 160-163.

Dr. Mithal Hassan
Nuclear Medicine Department
Faculty of Medicine
Kuwait University
P.O. Box 24923 Safat
13110, Kuwait

J. Clin. Chem. Clin. Biochem. / Vol. 25, 1987 / No. 8 